\title{
A GIS for the planning of electrical earthing
}

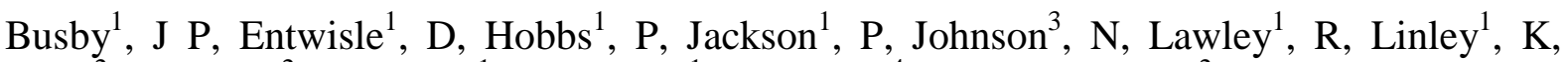 \\ Mayr $^{2}$ T, Palmer ${ }^{2}$, R, Raines ${ }^{1}$, M, Reeves ${ }^{1}, \mathrm{H}$, Tucker ${ }^{4}$, S and Zawadzka ${ }^{2}$, J. \\ ${ }^{1}$ British Geological Survey, Keyworth, Nottingham, NG12 5GG \\ ${ }^{2}$ National Soil Resources Institute, Cranfield University, Bedfordshire, MK43 0AL \\ ${ }^{3}$ Western Power Distribution (West Midlands) plc, 234 Victoria Road, Fenton, Stoke-On- \\ Trent, Staffordshire ST4 2JA \\ ${ }^{4}$ UK Power Networks, Energy House, Carrier Business Park, Hazelwick Avenue, Crawley, \\ RH10 1EX
}

\section{Abstract}

When creating an electrical earth for a transformer with vertically driven earthing rods, problems can arise either because the ground is too hard or because the ground is too resistive to achieve the required earthing resistance. To assist in the planning of earthing installations a GIS layer has been created. In its simplest form it consists of a colour coded map that indicates the most likely earthing installation; a single vertically driven rod (indicated by dark green); multiple vertically driven rods (indicated by light green); a horizontal trench, where a rod installation is unlikely (indicated by yellow); and for difficult ground, a specialist installation, i.e. drilling (indicated by red). However, the GIS can be interrogated to provide site specific information such as site conditions, likely depth of installation and quantity of earthing materials required. The GIS was created from a spatial model constructed from soil, superficial and bedrock geology that has been attributed with engineering strength and resistivity values. Calculations of expected earthing rod resistance, rod/trench length, and all possible combinations of ground conditions have been compared with the 'likely' conditions required for each of the four proposed installation scenarios to generate the GIS layer. The analysis has been applied to the electrical network distribution regions of Western Power Distribution in the English Midlands and UK Power Networks that covers East Anglia, London and the southeast of England. Since the spatial model that underlies the GIS has been constructed from national databases the analyses can be extended to other regions of the UK.

\section{Introduction}

In the UK it is a requirement of the Electrical Safety, Quality and Continuity Regulations (Anonymous 2002) that any voltage source on a high voltage network is connected with an electrical earth at, or as near as is reasonably practicable to, the source of voltage. In rural areas, where there is no buried earthing infrastructure, earthing entails driving rods, or grids of rods into the ground until the electrical resistance between the earthing system and the general mass of earth has reached a low enough value to protect the source of voltage. Correct installation of an earthing system is vital to comply with regulations, to protect persons or animals against the danger of electric shock and maintain the proper function of the electrical system. There are four components that simplify the installation of good earthing, 1) ground that is sufficiently soft to allow the driving of earthing rods to depth, 2) ground of low resistivity, 3) a low contact resistance between the earthing rod and the ground and 4) a low resistance earthing rod that is strong enough to be driven into the ground. Earthing rods are usually made of steel, clad with either copper or stainless steel. They must have a diameter that is a large enough to allow a high current to pass without damaging the 
rod. Alternatively copper rope can be attached to a steel rod and pulled to depth by the driven steel rod.

The majority of rural electrical supplies are delivered from $11 \mathrm{kV}$ transformers mounted on wooden poles. The earthing resistance required for these transformers is $10 \Omega$. In the simplest case this would be achieved with a single earthing rod, driven by a hand held or mechanical hammer into ground of low resistivity and strength whose electrical properties will not change significantly with the seasons. In the worst case when the ground is too strong to allow the driving of rods, it may be necessary to dig a trench into the soil layers above very strong bedrock with a mechanical digger and insert a horizontal earthing strip. Such installations are expensive and may require large quantities of earthing materials to achieve the earthing resistance. Often it may be possible to drive a rod into the ground, but the ground is too resistive to achieve the earthing resistance from a single rod and so multiple rods are required, offset from each other by three to four meters.

Installers of earthing systems are electrical engineers and therefore have little a priori knowledge of the ground conditions they are going to face. This can be costly as they cannot plan in advance the type of earthing installation that will be required. This paper describes a Geographical Information System (GIS) that gives a site specific prognosis as to the type of earthing required for $11 \mathrm{kV}$ transformers. The prognoses were derived from an evaluation of the engineering strength and electrical resistivity of the ground. It was undertaken under contract to Western Power Distribution (East and West Midlands), whose distribution area covers the English Midlands and UK Power Networks, that covers East Anglia, London and the southeast of England (see Figure 1). New prognoses will improve the planning of earthing installations, improving the efficiency of installation by improved estimations of equipment and quantities of earthing rods.

\section{Methodology}

The unconsolidated layer at the surface of the earth is referred to as soil. Engineering geologists refer to engineering soils (a concept of three-phase material composed of rock or mineral particles, water and air) that can be many metres in thickness. However, soil scientists define soil as a layer at the earth's surface containing living matter and capable of supporting plants, which in the UK has a maximum thickness of about $1.5 \mathrm{~m}$. In the work described here a three layer earth is defined as; an upper layer of soil as defined by soil scientists; a second layer of superficial geology comprising unconsolidated sediments of mainly Quaternary age (the engineering soils of the geologist) and a basal underlying bedrock geology. An earthing installation might be installed in any combination of these layers, but rods need to be inserted $0.9 \mathrm{~m}$ below ground level to avoid interference from farming activities. Figure 2 illustrates the four main installation scenarios for which engineers would like a priori knowledge. An additional factor to be considered concerns areas of peat where installers prefer not to earth equipment due to the nature of the deposit in terms of earthing security (weak material), variable earth resistance (drying out) and aggressive environment (corrosion to metalwork).

In order to fully resolve earthing requirements at any site, a three-dimensional soil-geology model with a spatial resolution of sub-1 m metre accuracy would be required. Such a model is currently unavailable as the necessary volume of site-specific data does not exist. However, it is possible to utilise two dimensional data within a GIS to emulate the typical soil-geology scenarios that are commonly found in the UK. These data must be attributed with engineering strength and electrical resistivity values. The indicative earthing installation prognosis for each substation site can be generated from the GIS as an extended traffic light system: 
- Dark green: Installation most likely to be a single rod installation.

- Light green: Installation most likely to be a multiple rod installation.

- Yellow: Installation most likely to be a horizontal trench.

- Red: $\quad$ Ground conditions preclude installation other than via drilling/specialist installation.

Sub-categories are possible, i.e. multiple rod installation most likely, but could be a single rod, and indications of likely quantities rods, and for trenched installations, an indication of appropriate equipment are also calculated.

The GIS consists of a spatial framework built from the soil and geology layers. This has then been attributed with resistivity and engineering strength values. Where measured values are not available they have been modelled or estimated. Application of the appropriate earthing resistance formulae (for rod and horizontal strip) has generated a site specific prognosis for the most likely earthing installation to achieve a $10 \Omega$ earthing resistance. Each of these steps is described in more detail below.

\section{Construction of the spatial framework}

A two-dimensional representation of a simple three-layered-block model comprising soil, superficial geology and bedrock has been constructed. The data layers utilised are listed in Table 1. The BGS DigMapGB50 geology map and superficial thickness data have been spatially merged into a new single layer. This layer provides the primary spatial framework for the earthing model and contains all the known spatial combinations of expected geology variation, including geological deposit/rock type expected below the soil layer, as well as rock type at depth. This layer also provides an approximation of the thickness of superficial deposits classified as:

- Soil over rock (or bedrock at surface)

- $1 \mathrm{~m}$ to $5 \mathrm{~m}$ of superficial deposits present

- $5 \mathrm{~m}$ to $10 \mathrm{~m}$ superficial deposits present

- $10 \mathrm{~m}+$ superficial deposits present

\section{Attribution with resistivity values}

Measured resistivity values comprise the prime datasets for resistivity attribution of the spatial model. However, there are very few data for UK soils and those for geology are not evenly distributed. It has therefore been necessary to model both soil and geology resistivities. Earth materials are heterogeneous and the quantity and salinity of pore water has a major impact on intrinsic resistivity. Soil resistivity varies widely as it is influenced by above-ground environment factors, such as rainfall and temperature, which act both on a daily and seasonal basis. The literature provides broad ranges of resistivity for generally illdefined soil texture classes such as 'sand', 'clay', and 'chalk', which are usually related to the engineering classification of soil. There are few data in the literature relating measured soil resistivity values to particle size distribution, moisture or temperature. Soil resistivity data are never presented alongside soil temperature and soil moisture data at the time of measurement. It is therefore difficult to interpret the broad ranges of resistivity given in the literature for the broad soil texture classes.

\section{Measured geological resistivities}


Measured values of field resistivities for geology are available from electrical surveys. The majority of these comprise resistivity soundings where a linear four electrode array is expanded from a central point resulting in penetration of the electrical current to greater depths. The recorded data comprise apparent resistivities which are weighted averages of the resistivities of the geological units through which the electrical current has passed. If the geology is assumed to be horizontally layered and homogeneous then it is a simple task to interpret the soundings and assign intrinsic resistivities to each of the geological units. Resistivity data are also collected in the laboratory on small cores of material, but these data have not been used due to problems with upscaling from the laboratory to field, sample disturbance and changes in pore water salinity. Similarly data from wireline logging tools have not been incorporated as these collect data below the zone of interest for this study.

The BGS National Resistivity Sounding Database (Barker et al., 1996) contains the raw resistances from around 8,200 electrical soundings from across Britain. The soundings were derived over an approximately 30 year period by academia, geological consultancies and the BGS. The distribution of these data across southern England and Wales is shown in Figure 3. These data are stored with metadata describing the type of sounding array, array spacings, location, azimuth, units, bibliographic references etc. The metadata have been loaded into a GIS along with the BGS digital 50,000 scale bedrock geology, superficial geology and superficial thickness maps. Within the GIS the geological polygons are identified by their LEX_ROCK code which is a unique rock name and lithology. Thus the resistivity interpretation is at the 50,000 scale It is thus possible to select a representative suite of soundings for each LEX_ROCK code and identify those codes where there are no data. The superficial thickness map indicates the total thickness of superficial cover and thus provides a constraint on the depth of the upper superficial layers in the resistivity interpretations. These results have been supplemented with data from the BGS Local Geophysical Surveys Metadata Base that references resistivity interpretations spanning many years that include data to investigate sand and gravel resources and data collected to aid geological mapping. The result is 2700 interpreted resistivities spanning 87 unique LEX_ROCK codes. Out of the 1427 LEX_ROCK codes that cover the Western Power Distribution (East and West Midlands) and UK Power Networks distribution areas this may seem a small number. However, many of the rocks attributed with different LEX_ROCK codes have very similar electrical properties, for instance there are 206 superficial geology polygons with a lithology of sand and gravel and 21 of diamicton.

\section{Resistivity modelling}

There are no measured resistivity data for the soils and, as indicated above, only a proportion of the geology is covered by measured data. It has therefore been necessary to undertake resistivity modelling for both the soil and geology layers.

\section{Soil layer}

Deep driven earthing rods are inserted through the soil and are largely located in the underlying geology and rely on the electrical properties of these materials to achieve satisfactory resistance. However, trench systems are placed in soil above hard bedrock and the electrical properties of the soil are critical in achieving the required earthing resistance. LandIS, the Cranfield University 'Land Information System', is an environmental information system containing soil and soil-related information for England and Wales. It includes soil maps at a variety of scales as well as corresponding soil property and agro-climatological data. Inherent soil resistivity values were calculated for each soil series based on the modal particle size distribution of their constituent soil horizons. The effect of changes in soil 
moisture content has been estimated by using pedo-transfer functions based on particle size distribution, bulk density and organic carbon content; applied to calculate water content at field capacity and water content at wilting point (Hollis \& Lilly, 2008). Water content at field capacity is chosen to represent a typical winter wetness state of soil and water content at wilting point occurs in dry summer months. In order to calculate the relationship between soil resistivity and soil temperature, soil characteristics were collated for each soil series according to methods described in Sharpley \& Williams (1990). The average soil temperature at the centre of each soil layer is a function of the damping depth and the depth weighting factor. The damping depth refers to the depth at which the soil temperature remains almost constant and corresponds to the long-term annual air temperature and is a function of bulk density and soil moisture content. The depth weighting factor governs temperature changes between the soil surface and the damping depth. For the calculation of the damping depth, the average annual temperature was calculated from monthly mean maximum and minimum temperatures for the period 1971 to 2000 (Meteorological Office, 2007) .

The field capacity and wilting point moisture contents were calculated for all horizons of all soil series. Resistivity values were then calculated for these moisture values in all horizons. Soil temperature was also calculated for the coldest and warmest month. Typical resistivity values were then calculated for all soils at these temperatures. For each soil the worst-case scenario (maximum soil resistivity) was calculated based on these data for all horizons.

\section{Superficial and bedrock geology layers}

The resistivity of a partially saturated, 'water wet' porous medium can be estimated from the relationship (Archie, 1942)

$$
\rho=\frac{\rho_{w}}{\left(\varphi^{m} S_{w}^{n}\right)}
$$

Where $\rho$ is the resistivity of the porous medium, $\rho_{\mathrm{w}}$ is the resistivity of the saturating water, $\varphi$ is porosity as a ratio, $S_{\mathrm{w}}$ is the degree of water saturation and the parameters $m$ and $n$ are designated cementation and saturation exponents. This relationship is only applicable when the electric current flows only within the pore fluid. To incorporate the contribution from conductive clay matrices the effective medium model of Berg (2007) has been applied. This model describes resistivity-porosity and saturation relationships without the constraint of a non-conducting matrix and high conductivity pore water, inherent in Archie's approach. The input parameters for the modelling are $\rho_{\mathrm{w}}$ (pore water resistivity), $\rho_{\text {shale }}$ (clay or shale resistivity), $\varphi$ (porosity), $\mathrm{S}_{\mathrm{w}}$ (saturation), $\mathrm{V}_{\mathrm{shG}}$ (clay content), $\mathrm{M}_{\boldsymbol{s h}}$ and $\mathrm{M}_{\boldsymbol{s} \boldsymbol{a}}$ are the values of Archie's $m$ parameter for clay/shale and sand respectively, and $n$ is Archie's saturation exponent. The values for $m$ and $n$ are derived from empirical studies, e.g. it has been shown that $\mathrm{M}_{\mathrm{sa}}$ is dependent on grain shape (Jackson et al., 1978). The other input parameters can take on a range of values and so representative high and low values have been used, e.g. expected low and high values for the saturation content, in order to generate a high and low modelled resistivity for each geological unit defined by its LEX_ROCK code.

If it is assumed that the pore water resistivity of a geological deposit falls in the range of the resistivity of free water flowing over the deposit or nearby, then these data can be extracted from the BGS Streams Database, a component of G-BASE, the Geochemistry database. The data comprise around 76,000 water samples collected from rivers across the UK that are routinely tested for electrical conductivity. Statistical outliers have been rejected as being non-representative, which may be because of atypical local conditions, contamination or poor quality data. 
The low and high porosity values of fine-grained deposits and rocks are from direct measurement in the BGS laboratories, or calculated from void ratio or dry density held in the BGS National Geotechnical Properties Database. Porosity values for fine-grained deposits or those with a fine grained matrix will change near surface with changes in water content due to drought, causing decreases in porosity (shrinking), or due to rainfall increasing porosity (swelling). The zone of moisture content change, the 'active zone', is usually confined to the top $1.5 \mathrm{~m}$ but may be increased to $3 \mathrm{~m}$ or more in the presence of tree roots (Driscoll, 1983; Jones and Terrington, 2011). The routine measurement of undisturbed porosity of coarsegrained deposits, such as sands and gravels, is often impractical using standard site investigation methods and is, therefore, not reported in site investigation reports. Indicative porosity value ranges are taken from the literature for materials of similar particle size distribution. These values are then adjusted for the relative density assessed from the Standard Penetration Test (N value) data (British Standards Institute, 1999, Clayton 1995) held in the BGS National Geotechnical Properties Database. For instance, those sand and gravels of similar particle size distribution that were classified as very loose to loose were given a porosity range weighted towards higher indicative values, whereas, those classified as dense or very dense were given a porosity range weighted towards lower indicative values.

It is assumed that all units are, for some part of the year, saturated within a metre or so of the surface, therefore, the high saturation value is $100 \%$. During dry weather the saturation will reduce near surface and the reduction in saturation depends on the length of time of the dry weather, the lithology and the level of the water table or perched water table within the ground. Coarse-grained units will dry out more and to greater depths than fine-grained units. More dense units will dry out less than less dense units. However, in most situations fully saturated material is likely to occur within $10 \mathrm{~m}$ of the ground surface. Saturation is not measured directly during site investigations. The low and high values of saturation for finegrained deposits are calculated from water content, particle density and voids ratio data from the BGS National Geotechnical Properties Database. The low saturation values of coarse units are estimated. However, low values of saturation, say below $50 \%$, may occur near surface particularly in sand and gravel where the water table is at a few metres below ground surface.

The low and high clay content values for most of the geological units are from the BGS National Geotechnical Properties Database. Some units have little or no data recorded and values of similar deposits are used, for instance, all glaciofluvial sand and gravels are assumed to have similar values as are most of the River Terrace Deposits. Values for the clay/shale resistivity are taken from the hydrocarbon literature, e.g. Waxman and Smits (1968).

\section{Attribution of resistivity ranges}

Where a sufficient number of interpreted resistivities have been obtained for a geological unit a simple set of statistics have been derived comprising the mean, median, upper quartile and 90th percentile. As with the modelled resistivities both low and high resistivities have been derived from the measured data. This is defined as the upper quartile for the high resistivity value and the median for the low value. These two statistics remove the influence of end members of the measuements and hence reduces the impact of poor quality sounding curves. These high and low values are both considered in the installation scenarios, although it is the worst case that prevails. For those geological units with little or no field data the modelled values have taken precedence.

The resistance formulae used to calculate the earthing resistance are taken from Chow et al. (1996) and Energy Networks Association (2003). The formula for a single vertical rod is 


$$
R_{\text {rod }}=\frac{\rho}{2 \pi L}\left(\operatorname{Ln}\left(\frac{8 L}{d}\right)-1\right)
$$

and that for a horizontal rod/strip is

$$
R_{\text {strip }}=\frac{\rho}{2 \pi L}\left(\operatorname{Ln}\left(\frac{L^{2}}{h d}\right)\right)
$$

Where $R_{\text {rod/strip }}$ is the earthing resistance of the vertical or horizontal $\operatorname{rod}(\Omega), \rho$ is the resistivity of the soil or geological layer $(\Omega \mathrm{m}), \mathrm{L}$ is the length of $\mathrm{rod} / \mathrm{strip}(\mathrm{m}), \mathrm{d}$ is the diameter of the rod (m) and $h$ is the depth of burial of the horizontal rod/strip (m). For the cases where the vertical earthing rod penetrates more than one layer or where multiple rods are required appropriate combinations of the formulae have been applied.

\section{Attribution with engineering strength values}

\section{Soil layers}

In general most soil layers will be penetrable by driven rods, but impenetrable zones can occur because of the abundance of hard stones or by hard substrates such as gravel. Relevant data on stoniness and substrates were extracted from the Cranfield University databases and are defined as follows. Stone abundance, defined as the percentage by volume of stones in a soil layer while stones are rock fragments $>2 \mathrm{~mm}$ across (longest dimension). A scale of descriptions is shown in Table 2. Soils over gravel are soils containing layers which are very or extremely stony ( $>35 \%$ stones by volume). These impenetrable stony layers must be more than $0.15 \mathrm{~m}$ thick and start within $0.8 \mathrm{~m}$ of the soil surface.

\section{Superficial and bedrock geology layers}

The Superficial and Bedrock Engineering Strength and Density dataset has been created using a classification that has applied the geotechnical parameter ranges for strength and density as described by BS5930:1999: Code of practice for site investigations (British Standards Institute, 1999); see Figures 4 and 5. This classification has then been applied to all geological deposits that are encountered on the BGS's DigMapGB Superficial and Bedrock (1:50, 000 scale) geological data. Each deposit has been given a range of either strength or density values depending on whether the material is consolidated or granular in nature. This has then enabled a minimum and maximum strength to be estimated. A mixture of literature and, where possible, site specific drilling data has been extracted from site investigation borehole records held in the BGS National Geoscience Data Centre (NGDC) and the BGS National Geotechnical Database to aid in the classification of the dataset.

The strength attribution has been further categorised by the likelihood that a strength class will permit rod insertion or trenching via mechanical methods. Thus for each rock or geological deposit in the spatial framework it is possible to determine if the material is weak enough to penetrate with pushed rods, or requires trenching, or is too strong to be excavated using typical excavation methods. For the work described here it has been assumed that vertical rods would be pushed with a mechanical hammer. If some other form of driving force were used the penetration depth would change (i.e. blows from a hand held hammer would not be able to drive the rods so deeply). This is illustrated in Figures 4 and 5 by a sliding scale from red to green that indicates if rod penetration is possible. 
Bedrock that is penetrable by rods will mainly comprise mudstone. It is assumed that such bedrock will only be penetrated by up to $2 \mathrm{~m}$ of rod before friction precludes further rod insertion, although, locally, it is likely that, weathered bedrock will allow a deeper penetration. Therefore in calculating the earthing resistances, only a maximum of $2 \mathrm{~m}$ penetration into bedrock is considered.

\section{Determination of earthing installation scenarios}

Calculations of earth resistance for all the combinations of low/high resistivity, of each geological layer within the spatial framework are made, taking into account the degree of likely rod penetration that can be expected for each layer in the spatial framework. These provide an estimate of likely earthing resistance for each layer, which can then be compared with the required resistance of 10 . These minimum/ maximum values of rod/trench also provide an estimate for the likely quantity of material needed to complete the site installation.

The calculations of expected earthing-rod resistance, rod/trench length, and all possible combinations of ground conditions are then compared with the 'likely' conditions required for each of the four proposed installation scenarios. For example, the data is filtered to identify areas where an earthing resistance of $10 \Omega$ can be met by a single rod inserted into the 'least' favourable conditions; or where least favourable conditions preclude $\mathrm{a} 10$ earthing resistance, but more favourable conditions allow it (i.e. a single rod is 'possible' given best case attributes, but a multiple rod is more likely) or where the presence of stronger rock precludes any type of rod/trench installation.

The methodology takes a 'pragmatic' approach wherever possible, i.e. the system will assume any form of installation is possible until proven otherwise. A decision tree to illustrate the methodology is shown in Figure 6 and is executed in the following manner:

1. Data filtering to identify areas that are unsuitable for rods.

2. Data filtering of areas unsuitable for rods to identify where none of the installation methods will be successful

3. Data filtering of remaining areas to determine if characteristics meet the criteria for a single rod, or whether multiple is possible.

4. Secondary data filtering for areas of Trench-only installation to identify equipment needed.

5. Secondary calculations for areas of multiple rod installation to determine if a trench installation is more appropriate.

6. Secondary data filtering for areas of single rod installation to determine likelihood of premature stoppage (and hence suggest a multiple rod installation) via spatial comparison.

The modelled data is thus classified into four likely installation scenarios: single-rod, multiple-rod, trench and special. Each of these likely scenarios is then refined into subcategories so that installers can envisage their options when preparing to install at any location. The twelve possible installation scenarios are shown in Figure 7 and are described below. 


\section{Single rod installation}

A single rod installation is possible when the worst case scenario of the soil-geology combination (high resistivity, maximum strength and shallowest penetration depth) indicate that the $10 \Omega$ earthing resistance can be achieved with a single rod. The rod may be embedded solely in the soil/superficial geology or may also penetrate up to $2 \mathrm{~m}$ of bedrock. In some cases local conditions may indicate the potential to stoppage for rod insertion (typically gravel within a clayey deposit) in which case the possibility of a multiple rod insertion is indicated by the SINGLE-MULTIPLE subcategory.

\section{Multiple rod Installation}

Areas of this status are characterised by having near surface geology of any type that can be penetrated by a rod and providing a resistance of $10 \Omega$ or less with a number of rods. Multiple rods often occur due to limited penetration caused by stoppage in the soil or superficial geology (i.e. unpredictable gravel content) or by shallow superficial cover over impenetrable bedrock. In areas where these factors are known to be variable (i.e. there is the possibility of deeper rod penetration) then they are categorised as MULTIPLE_SINGLE. Conversely, some multiple rod scenarios in bedrock of mudstone may require so many rods that the earthing is more efficiently installed via a horizontal trench. This is particularly so where the strength of rock on site is notably variable due to the presence of thin sandstone or limestone beds. The possibility of a trench at a multiple rod site is flagged by the MULTIPLE_TRENCH subcategory.

\section{Trench installation}

The main criterion for this scenario is that there is no apparent penetrability of the geology by a vertical rod, but trenching via backhoe is possible. A secondary reason for opting for this scenario is that a trench offers a more effective solution than any multiple rod installation that requires many rods for reasons of limited penetrability or high resistivity. The TRENCH scenario has four subcategories, as follows:

- The TRENCH_MULTIPLE subcategory indicates where local conditions might allow a multiple rod solution. This occurs because the upper resistivity of the soil-geology combination is not as high as expected, or the depth to impenetrable bedrock is greater than expected.

- The TRENCH_MULTI_B subcategory characterises sites where a combination of readily draining superficial and readily draining bedrock geology are present (e.g. sand and gravels, underlain by sandstones, or similar free-draining hard bedrock). In these circumstances the apparent resistivity of the soil-geology is likely to be very high resulting in a trench solution. However, where local conditions indicate that the ground is not free draining (i.e. in a river valley) or if rod penetration is not impeded, then the sites will probably provide a multiple rod installation, rather than a trench.

- The TRENCH_P subcategory is reserved for all trench scenarios where peat is present at the site. The presence of peat can cause problems for installation in terms of site access, and security of the earthing, although it does provide an alternative installation medium for the earthing electrode.

- The TRENCH_B subcategory represents areas where chalk bedrock underlies the soil at a site. This category is highlighted because the chalk lithology can prove highly variable in its strength due to the presence or absence of flint layers and it also 
weathers in an unpredictable manner creating karstic features. Hence all other installation types may be possible.

The TRENCH scenarios are provided with additional information concerning the type of trenching equipment likely to be needed on site. In effect, this is an estimation of equipment type rated by the strength of the material being trenched. The equipment needed to dig a $1 \mathrm{~m}$ deep trench is estimated from BGS archives of engineering strength, taking into account nearsurface weathering and whether the bedrock is 'rippable' (fragmented layers that can be 'prised' out by excavator). There are two classes of trench equipment: 1. Compact (i.e. 'bobcat' mini-excavator) and, 2. Standard (i.e. JCB excavator/backhoe). Note that all superficial geology deposits are considered trenchable, and that a 'compact' backhoe is considered suitable for providing trenching when connecting multi-rod arrays.

\section{Special installation}

In this scenario it is impossible to penetrate below the soil layers because there is no penetrability of the geological deposits. A specialist installation might involve drilling into the bedrock to create the electrical earth. The SPECIAL scenario includes one subcategory (SPECIAL_P) for locations covered in Peat. The presence of peat can cause problems for installation in terms of site access, and security or the earthing, although it does provide an alternative installation medium for the earthing electrode.

The special scenario can be mitigated by determining weathering characteristics of bedrock (it may be 'just' trench-able where weathered) or may be subject to localised 'karst' features that enable trench/rod penetration in very specific and non predictable circumstances (trenching of soil may reveal suitable candidate locations). Alternatively, where soil profiles greater than $90 \mathrm{~cm}$ are present (thicker soils develop in landscape hollows, or via artificial building up of soil layers) an in-soil trench is possible. The GIS will not calculate such mitigating scenarios and so there are no further sub-categories, but it will flag their existence as a possibility.

\section{Model Output}

The two electrical distribution areas (shown in Figure 1) represent very different geological, pedological and geographical landscapes. The Western Power Distribution (East and West Midlands) area is mostly underlain by Carboniferous, Triassic and Jurassic bedrock, with a sporadic and generally thin superficial cover mainly related to the Severn, Avon and Trent river systems. The UK Power Networks area is underlain by Jurassic, Cretaceous and Tertiary Bedrock, with thick superficial cover in East Anglia and sparse superficial cover in the south-east. Both catchment areas are represented by single rod, multiple rod, trench and specialised installation scenarios.

\section{Western Power Distribution (East and West Midlands) distribution area}

The Western Power Distribution (East and West Midlands) area prognosis for a $10 \Omega$ earthing resistance is shown in Figure 8 . The area is dominated by multiple rod installation scenarios ( $\sim 43 \%)$. Trench installations are predicted for $\sim 22 \%$ of the area, particularly along the northern and western margins, whilst special installation is predicted to cover a further $\sim 18 \%$. Single rod installations are expected in the remaining $\sim 17 \%$ of the area, generally in the eastern half of the area.

\section{Single rod installations:}


These installations are most likely where there are thicker sequences of lower resistivity, lacustrine silts or glacial till. In areas where the superficial cover becomes thinner there is still a high potential for a single rod installation, but there is a slight risk that premature stoppage by gravel within the drift, or limited penetration into the underlying bedrock which may force an occasional use of multiple rods (these are classed as SINGLE-MULTIPLE).

\section{Multiple rod installations:}

Multiple rod installations cover a wide range of pedological and geological combinations. In this area many of the multiple rod installations will be in:

1. higher resistivity, colluvium, river terrace gravels and sands over mudstone bedrock, or

2. soils over Triassic, Jurassic and Cretaceous mudstone bedrock, or

3. lower resistivity, alluvium, tills and lacustrine clays over impenetrable bedrock.

Superficial units of higher resistivity overlying mudstone bedrock will typically require a multiple rod installation because of localised dry conditions, and the installation may utilise some penetration into the bedrock as part of the earthing solution.

Installation into mudstone bedrock presents a challenge for rod insertion due to the strength of the material. In some areas the strength of the mudstone, or any harder interbeds of sandstone or limestone within, may prevent rod insertion. The risk of this is low, but these units are flagged as MULTIPLE-TRENCH within the GIS.

Superficial units of lower resistivity (usually alluvium, lacustrine deposits and till) overlying impenetrable bedrock will typically require a multiple rod insertion due to premature stoppage of the rods by the bedrock. However, the lower resistivity unit may be thick enough to allow for a single-rod installation in some circumstances. Such areas are classed as MULTIPLE_SINGLE in the GIS.

\section{Trench installations:}

Trench installations are typically associated with Silurian-Carboniferous mudstones and siltstones, Triassic and Jurassic sandstones and any rocks of mixed lithologies (thin alternating layers of different rock types). In general these units will be too hard to insert a mild steel earthing rod. However, it may, on occasion, be possible to insert rods into the weathered uppermost parts of these rocks, (where this is possible the prognosis is for a TRENCH-MULTIPLE installation). A small area of chalk bedrock occurs in the north east of the Western Power Distribution (East and West Midlands) area and this is identified by its TRENCH_B prognosis.

The complex TRENCH_MULTI_B scenario is represented in this area by glacio-fluvial gravels and river terrace gravels overlying dominantly Carboniferous, Triassic and Jurassic sandstone (all free draining). This installation scenario is provided to forewarn installers that local site conditions may be difficult and unpredictable (dry/stony ground).

\section{Special installations:}

Special installations in the Western Power Distribution (East and West Midlands) area are associated with Silurian, Devonian and Carboniferous limestones, sandstones and gritstone, and also Jurassic limestone bedrock. It may be possible to trench into the weathered uppermost part of these units, utilising tools to assist in 'ripping' the bedrock, but in general these rocks are problematic, and a shallow (sub-soil) installation may offer the best solution. Local site conditions will play a significant role in determining the success of the final installed array. 


\section{UK Power Networks distribution area}

The UK Power Networks area prognosis for a $10 \Omega$ earthing resistance is shown in Figure 9. This area is dominated by multiple rod installation scenarios ( 44\%), but with a significant number of rock-soil combinations offering single rod installations ( $30 \%$ of the area). Trench installations are expected for only 23\% of the area (and are strongly influenced by the occurrence of chalk), whilst special installations are limited to the hardest bedrock at surface and cover only $\sim 3 \%$ of the area.

\section{Single rod installations:}

These installations are most likely where there are thicker sequences of lower resistivity lacustrine silts or glacial tills. In areas where the superficial cover becomes thinner there is still a high potential for a single rod installation, but there is a slight risk that premature stoppage by gravel within the drift, or no penetration into the underlying bedrock may force an occasional use of multiple rods; such areas are flagged as SINGLE_MULTIPLE in the GIS.

\section{Multiple rod installations:}

Multiple rod installations cover a wide range of pedological and geological combinations. In this area many of the installations will be in:

1. higher resistivity, sand and gravel dominated superficial deposits overlying mudstone bedrock, or

2. Jurassic, Cretaceous and Tertiary bedrock of mudstone or sand (not sandstone), or

3. lower resistivity alluvial, colluvial, lacustrine and till deposits over impenetrable bedrock (notably chalk).

Superficial units of higher resistivity overlying mudstone bedrock will typically require a multiple rod installation, and the installation will utilise some penetration into the bedrock as part of the earthing solution. The main complication with these installations is premature stoppage by gravel units within the superficial deposits.

Installation into mudstone bedrock presents a challenge for rod insertion due to the strength of the material. In some areas the strength of the mudstone, or any harder interbeds of sandstone or limestone within, may prevent rod insertion. The likelihood of this is low, but these units are flagged as MULTIPLE-TRENCH within the GIS

Superficial units of lower resistivity (typically alluvium, till and colluvium) overlying impenetrable bedrock will typically require a multiple rod insertion. However, the lower resistivity of these deposits may be enough to allow for a single rod installation in some circumstances. Such areas are classed as MULTIPLE_SINGLE in the GIS.

\section{Trench installations}

Trench installations are typically associated with Jurassic sandstones, Cretaceous chalk and any rocks of mixed lithologies (thin alternating layers of different rock types). Chalk varies widely in hardness; the older chalk formations contain higher clay content (they are sometimes called 'marly' chalk) and are relatively soft, offering the potential for multiple rod insertions where weathered deeply. However, the younger chalk formations are locally very hard, and flint bearing, requiring trenching with heavy machinery and offering unpredictable trenching conditions. In general it is considered prudent to treat the chalk escarpment as an area likely to require a shallow trench installation (i.e. locally less than $0.9 \mathrm{~m}$ deep) and hence the TRENCH_B classification for all chalk substrates. 
The complex TRENCH_MULTI_B scenario is represented in this area by glacio-fluvial gravels and river terrace gravels overlying dominantly Jurassic, Cretaceous and Tertiary sandstones or sands (all free draining). This installation scenario is provided to forewarn installers that local site conditions may be difficult and unpredictable (dry/stony ground).

\section{Special installations:}

Special installations in the UK Power Networks area are associated with Jurassic sandstone and limestone bedrock. It may be possible to trench into the weathered uppermost part of these units, utilising tools to assist in 'ripping' the bedrock, but in general these rocks are problematical, and a shallow (subsoil) installation may be the best solution. Local site conditions will play a significant role in determining the success of the final installed array.

\section{Conclusions}

The GIS described here has been designed to assist in the planning of earthing to high voltage distribution systems. In its simplest form the derived maps can be viewed solely for the 'traffic light' prognoses that provide a simple, qualitative, assessment of the likely difficulty of creating an earth at a particular site. However, through a simple polygon enquiry the GIS can deliver semi-quantitative information on the most likely type of earthing arrangement that can be installed, its depth of installation and the quantity of materials that will be needed. As described the prognoses are for an earthing resistance of $10 \Omega$, but the calculations can be rerun for other solutions, e.g. $1 \Omega$ or $20 \Omega$. It is possible in the future that climate change may lead to changes in precipitation and temperature that may result in an increased or decreased ground resistivity, particularly if seasonal variations become more extreme. This in turn will lead to changes in earthing resistances required to protect transformers against these more extreme conditions. Warmer, dryer conditions will increase ground resistivity (requiring lower earthing resistances), whilst wetter, cooler conditions will decrease ground resistivity. The number of rods in a vertically driven multiple rods installation will decrease for a $20 \Omega$ solution but increase for $1 \Omega$. The analyses could also be re-run if the installation equipment were to change as the rod penetration traffic light can be moved against engineering strength and density.

The prognoses are designed to provide the 'most likely' installation scenario, but the methodology used to create them takes a conservative assessment of the data. This is to forewarn installers of potential difficulties, allowing appropriate planning and hopefully uneventful installation. Local site conditions, on the day of installation may prove easier (or, more difficult) to create the required safe earth. In general, many superficial and bedrock geology combinations allow for some form of vertical rod earthing array. The primary restriction on vertical rod installations is the strength of the geological materials, in particular the proximity of impenetrable bedrock. Where penetration by rod is possible the next critical factor is the resistivity of the substrate. This effectively governs the length of deep drive rod, allowing determination of single rod or multiple rod arrays. The multiple rod arrays are further assessed to determine if a trench array would be a more efficient earthing method given the large number of earthing rods that may be required. The 'trenchable' bedrocks are more prevalent in the Western Power Distribution (East and West Midlands) area, as are the areas requiring more specialised installation as a result of the Western Power Distribution (East and West Midlands) area being underlain by generally older and stronger rocks than those underlying the UK Power Networks area. Initial feedback on the effectiveness of the prognoses has been positive with the companies reporting generally good agreement between the predictions and the earthing arrays installed in the ground. The analyses can be extended to other regions of the UK, since the databases used to construct the spatial model are national. Regions underlain extensively by hard bedrock (combined with shallow superficial 
deposits and thin soils) may require a trench solution to be rated as optimum (a green traffic light) since vertically driven rod solutions are likely to be few and far between.

The prognoses include a preliminary assessment of susceptibility to hydrological variability (the geological resistivities include a degree of moisture variation; free draining deposits are processed as a separate prognosis, and the vertical rod systems optimise the chance of accessing more consistent ground moisture at depth). However, where shallow trench systems are installed, or where the site is underlain by free draining soils and geology, the effects of soil moisture and near-surface water tables may create seasonal variability in the earthing capability of the installed array. It is planned to include seasonal variability in future releases of the Earthing Information GIS.

\section{Acknowledgements}

This paper is published by permission of the Executive Director of the British Geological Survey (NERC).

\section{References}

Anonymous, 2002. Electrical Safety, Quality and Continuity Regulations, 2002. Statutory Instruments 2002 No. 2665 Electricity, The Stationary Office, London.

Archie, G.E., 1942. The electrical resistivity log as an aid in determining some reservoir characteristics, Transactions of the American Institute of Mining, Metallurigical and Petroleum Engineers, 146, 54-62.

Barker, R., Blunk, I and Smith, I., 1996. Geophysical considerations in the design of the UK National Resistivity Sounding Database. First Break, 14, 45-53.

Berg, C.R., 2007. An effective medium algorithm for calculating water saturations at any salinity or frequency. Geophysics, 72, E59-E67.

British Standards Institute, 1999. BS 5930:1999 Code of practice for site investigations. Available from: British Standards Institution Standard Sales, 389, Chiswick High Rd, London, W4 4AJ. ISBN 0580330591.

Chow, Y.L., Elsherbiny, M.M. and Salama, M.M.A., 1996. Resistance formulas of grounding systems in two-layer earth. IEEE Transactions on Power Delivery, 11, 1330-1336.

Clayton, C R I. 1995. The Standard Penetration Test (SPT): Methods and use. CIRIA report 143. CIRIA, London.

Driscoll, R. 1983. The influence of vegetation on the swelling and shrinking of clay soils in Britain. Quarterly Journal of Engineering Geology and Hydrogeology, 38, 93-105.

Energy Networks Association, 2003. Engineering Recommendation S34 1986. A guide for assessing the rise of earth potential at substation sites. (Engineering Directorate; Energy Networks Association; London).

Hollis, J.M. and Lilly, A., 2008. Multiple regression analysis of Measured Water Retention Data from England, Wales and Scotland. In Dufour, M.J.D. Linking SEISMIC with the Aquatic Ecosystem Database. Defra Project PS2212.

Jackson, P.D., Taylor-Smith D. and Stanford P.N., 1978. Resistivity-porosity-particle shape relationships for marine sands. Geophysics 43, 1250-1268.

Jones, L D, Terrington, R. 2011. Modelling volume change potential in London Clay. Quarterly Journal of Engineering Geology and Hydrogeology, 44, 109-122. 
Meteorological Office, 2007. 1971 -2000 annual and monthly averages. Averages for a range of weather elements for meteorological stations across the UK. http://www.metoffice.gov.uk/climate/uk/averages/19712000/, accessed 2007.

Sharpley, A.N. and Williams, J.R., 1990. EPIC Erosion/Productivity Impact Calculator: 1. Model Documentation. U.S. Department of Agriculture Technical Bulletin No. 1768.

Waxman, M. H., and L. J. M. Smits, 1968, Electrical conductivities in oilbearing shaly sand: Society of Petroleum Engineers Journal, 8, 107-122. 


\section{List of Tables and Figures}

Table 1. Datasets used in building the spatial framework.

Table 2. Stone abundance within soil layers, defined as the percentage by volume of stones in a soil layer while stones are rock fragments $>2 \mathrm{~mm}$ across (longest dimension).

Figure 1. The Western Power Distribution (East and West Midlands) (green) and UK Power Networks (East Anglia, London and the southeast of England) (blue) electrical distribution areas. The two transparent rectangles are areas of representative soils and geology that were used to test the methodology before it was applied to the whole area. Co-ordinates are British National Grid (km).

Figure 2. The four installation scenarios for the electrical earthing of $11 \mathrm{kV}$ transformers. Soil is represented as a brown layer, superficial geology is stippled and the bedrock geology is shown as inclined bricks.

Figure 3. Distribution of data held in the BGS National Resistivity Sounding Database across southern England and Wales. The electrical distribution areas of Western Power Distribution (East and West Midlands) and UK Power Networks are also shown (see Figure 1).

Figure 4. Engineering strength classification for superficial and bedrock geology. The Standard Penetration Test (SPT) for granular soils is determined from the number of blows $(\mathrm{N})$ from a $45 \mathrm{~kg}$ hammer required to drive a rod $300 \mathrm{~mm}$ into the ground. The strengths and densities have been assessed for rod penetration $($ No $=$ red, Maybe $=$ yellow and Yes $=$ green $)$. This is an arbitrary scale, shown here for illustration only, that can be moved up or down depending on the method for driving the rods.

Figure 5. Density classification for unconsolidated material. The SPT and the strength and density assignment (coloured scale) are as shown in Figure 4.

Figure 6. Application of the logic to determine the type of electrical earthing installation, depicted as a decision tree.

Figure 7. Electrical earthing prognoses and descriptions comprising four main categories split into 12 sub categories.

Figure 8. The Western Power Distribution (East and West Midlands) area electrical earthing prognoses for an earthing resistance of 10 ohms. For location see Figure 1. The approximate percentage distribution (by area) of the different installation scenarios are single rod, $17 \%$; multiple rod, $43 \%$; trench, $22 \%$ and special $18 \%$. The influence of the geology on the earthing solution is indicated (see main text for explanation); solid arrows point to a specific region of the map, whilst multi-arrows point to an extended region.

Figure 9. The UK Power Networks area electrical earthing prognoses for an earthing resistance of $10 \mathrm{ohms}$. For location see Figure 1. The approximate percentage distribution (by area) of the different installation scenarios are single rod, 30\%; multiple rod, 44\%; trench, $23 \%$ and special 3\%. The influence of the geology on the earthing solution is indicated (see main text for explanation); solid arrows point to a specific region of the map, whilst multi-arrows point to an extended region. 


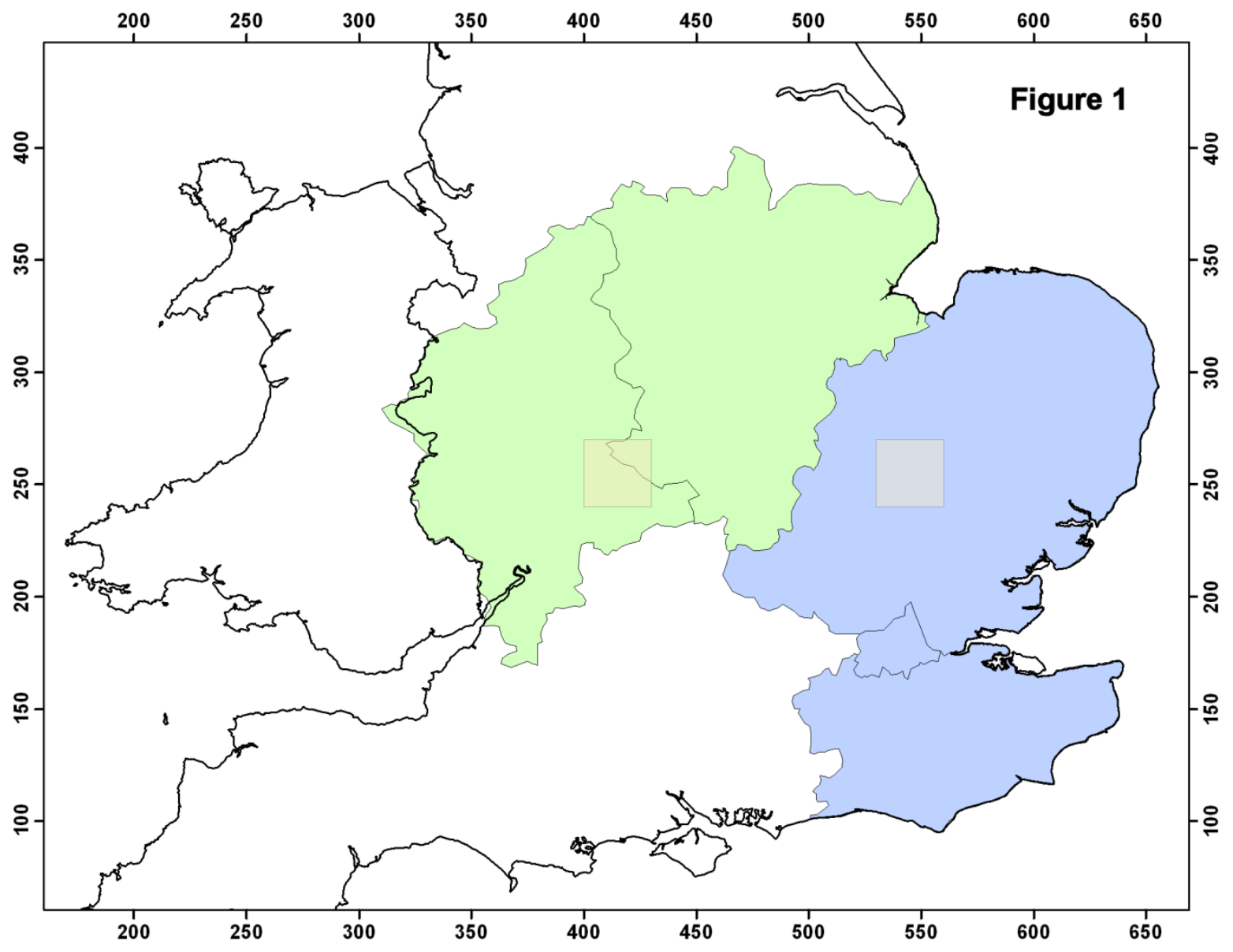

Figure 1 


\begin{tabular}{|l|l|l|l|}
\hline $\begin{array}{l}\text { Scenario 1: } \\
\text { Single rod installation }\end{array}$ & $\begin{array}{l}\text { Scenario 2: } \\
\text { Multiple rod installation }\end{array}$ & $\begin{array}{l}\text { Scenario 3: } \\
\text { Trench installation } \\
\text { Specialist installation }\end{array}$ \\
\hline & & &
\end{tabular}

Figure 2 


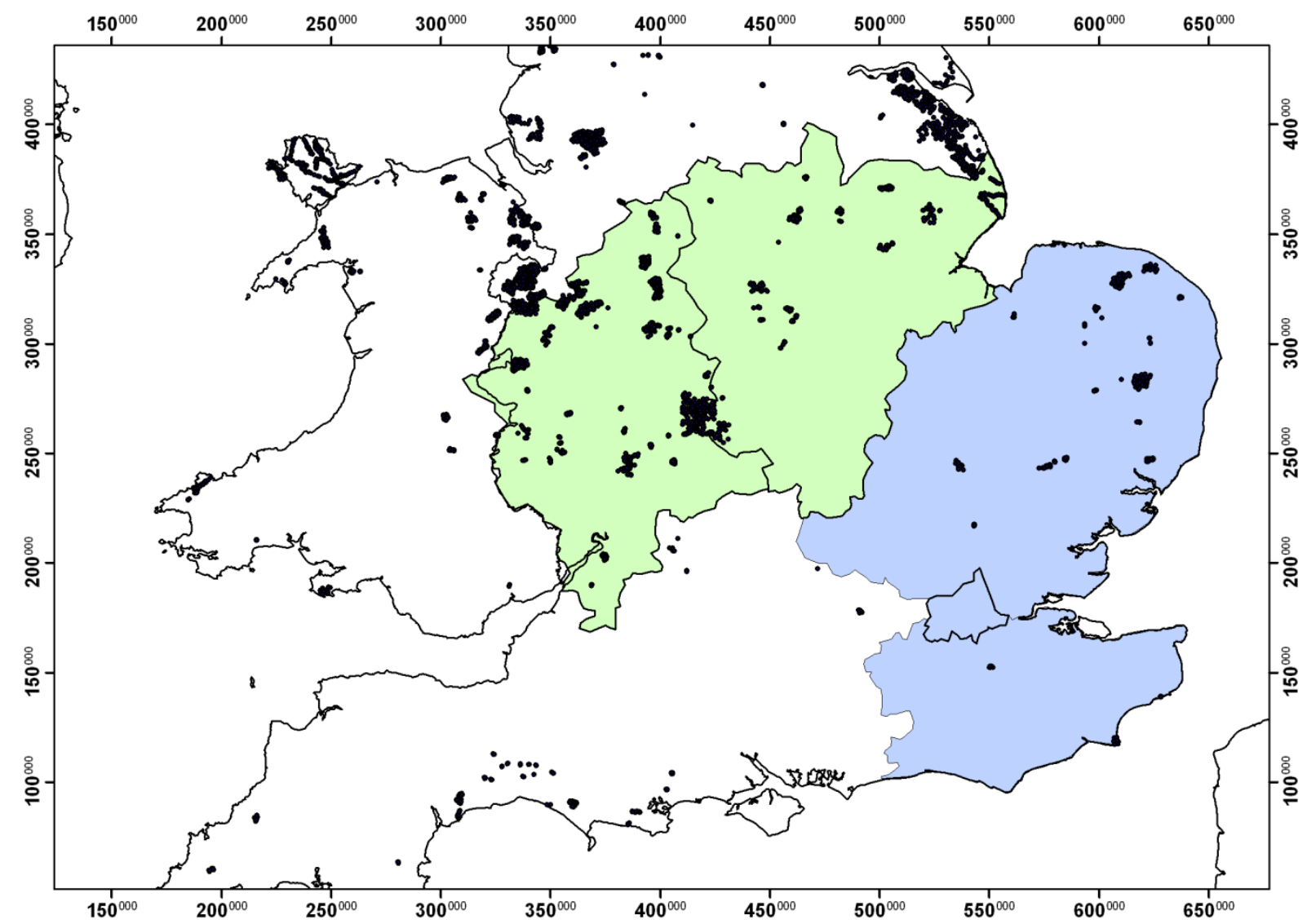

Figure 3

\begin{tabular}{|c|c|c|c|}
\hline & Term & $\begin{array}{c}\text { Uniaxial } \\
\text { Compressive } \\
\text { Strength (MPa) }\end{array}$ & $\begin{array}{c}\text { SPT N-values } \\
\text { (blows/300mm } \\
\text { penetration) }\end{array}$ \\
\hline \multirow{7}{*}{ 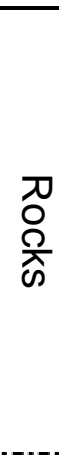 } & Extremely Strong & $>200$ & - \\
\hline & Very Strong & $100-200$ & - \\
\hline & Strong & $50-100$ & - \\
\hline & Moderately Strong & $12.5-50$ & - \\
\hline & Moderately Weak & $5.0-12.5$ & - \\
\hline & Weak & $1.25-5.0$ & - \\
\hline & $\begin{array}{c}\text { Very weak rock / hard } \\
\text { soil }\end{array}$ & $0.60-1.25$ & - \\
\hline \multirow{5}{*}{$\begin{array}{l}\frac{T}{\bar{D}} \\
\text { D } \\
\text { O } \\
\frac{0}{\omega}\end{array}$} & Very Stiff & $0.30-0.60$ & $>30$ \\
\hline & Stiff & $0.15-0.30$ & 15 to 30 \\
\hline & Firm & $0.08-0.15$ & 8 to 15 \\
\hline & Soft & $0.04-0.08$ & 4 to 8 \\
\hline & Very soft & $<0.04$ & $<4$ \\
\hline
\end{tabular}

Figure 4 


\begin{tabular}{|c|c|c|c|}
\hline & TERM & $\begin{array}{c}\text { SPT N-values } \\
\text { (blows/300mm } \\
\text { penetration) }\end{array}$ & $\begin{array}{c}\text { FIELD } \\
\text { ASSESSMENT } \\
\text { (very } \\
\text { approximate) }\end{array}$ \\
\hline \multirow{5}{*}{ 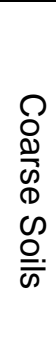 } & Very dense & $>50$ & \multirow{3}{*}{$\begin{array}{c}\text { Requires pick for } \\
\text { excavation. } 50 \mathrm{~mm} \\
\text { wooden peg hard to } \\
\text { drive. }\end{array}$} \\
\hline & Dense & 30 to 50 & \\
\hline & Medium dense & 10 to 30 & \\
\hline & Loose & 4 to 10 & \multirow{2}{*}{$\begin{array}{c}\text { Can be excavated } \\
\text { with spade. } 50 \mathrm{~mm} \\
\text { wooden peg easily } \\
\text { driven. }\end{array}$} \\
\hline & Very loose & $<4$ & \\
\hline \multirow{2}{*}{ 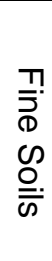 } & Compact & I & $\begin{array}{l}\text { Easily moulded or } \\
\text { crushed in fingers }\end{array}$ \\
\hline & Uncompact & I & $\begin{array}{l}\text { Can be moulded or } \\
\text { crushed by strong } \\
\text { pressure in the } \\
\text { fingers }\end{array}$ \\
\hline
\end{tabular}

Figure 5

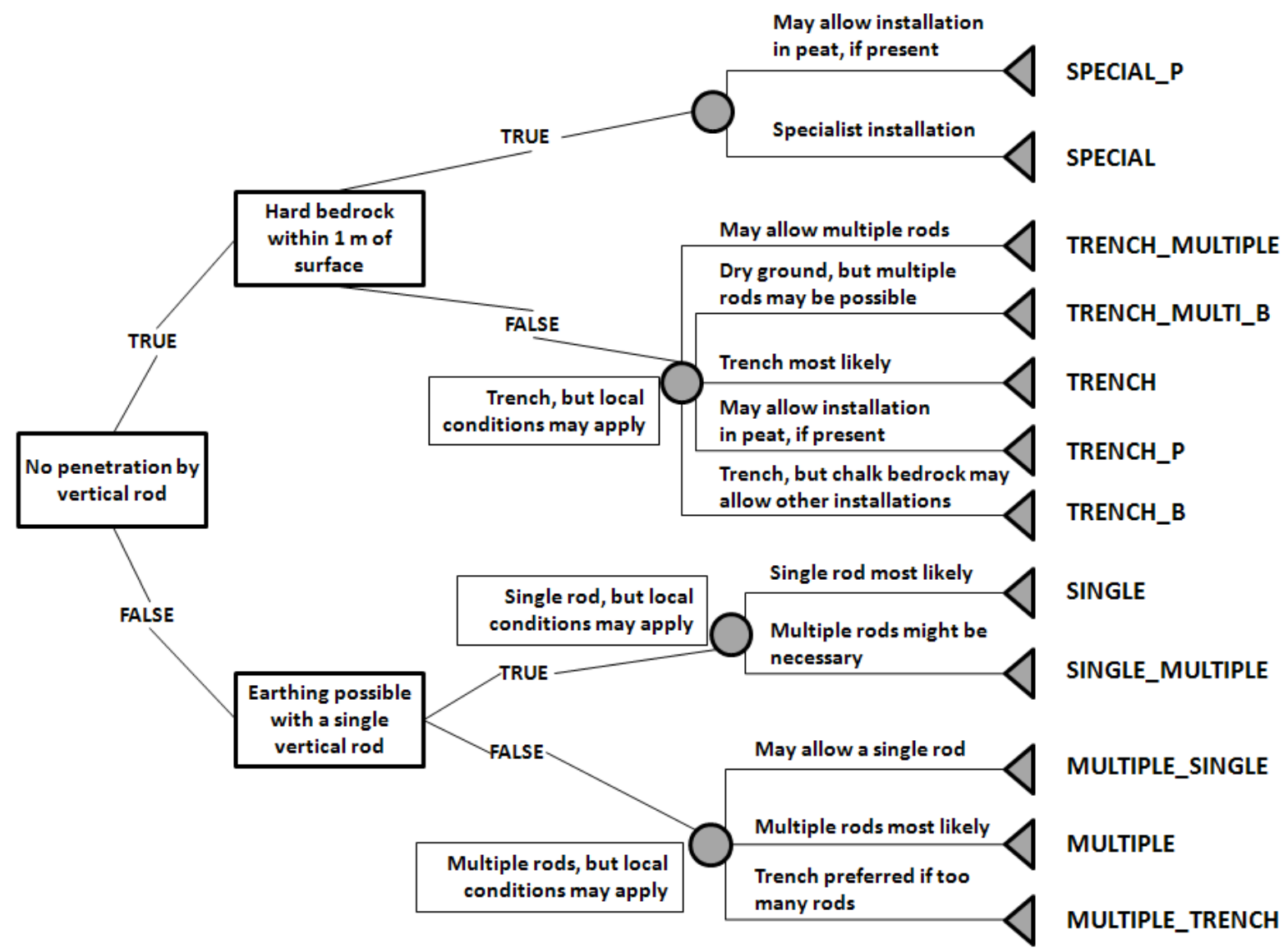

Figure 6 


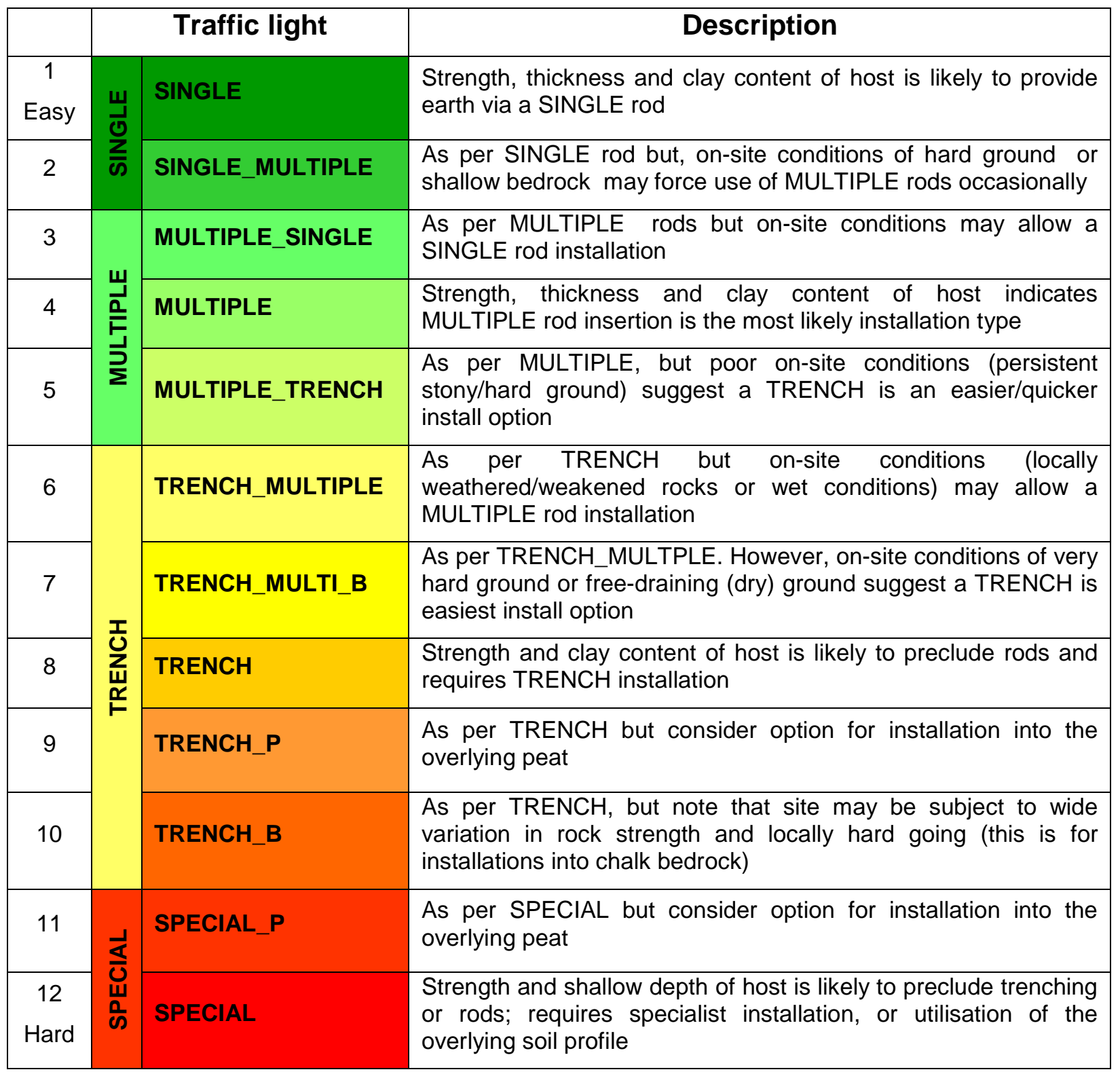

Figure 7 


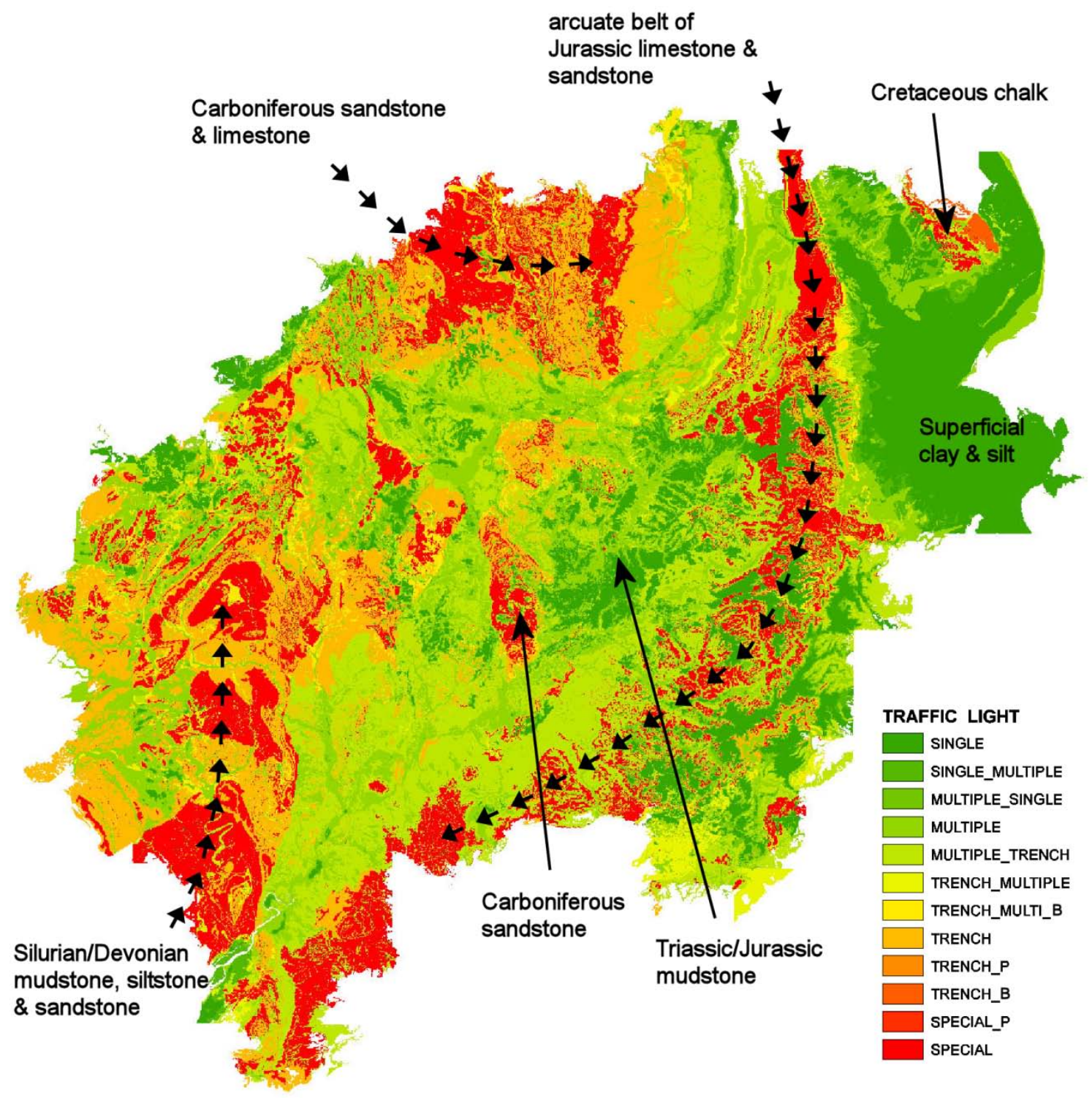

Figure 8 


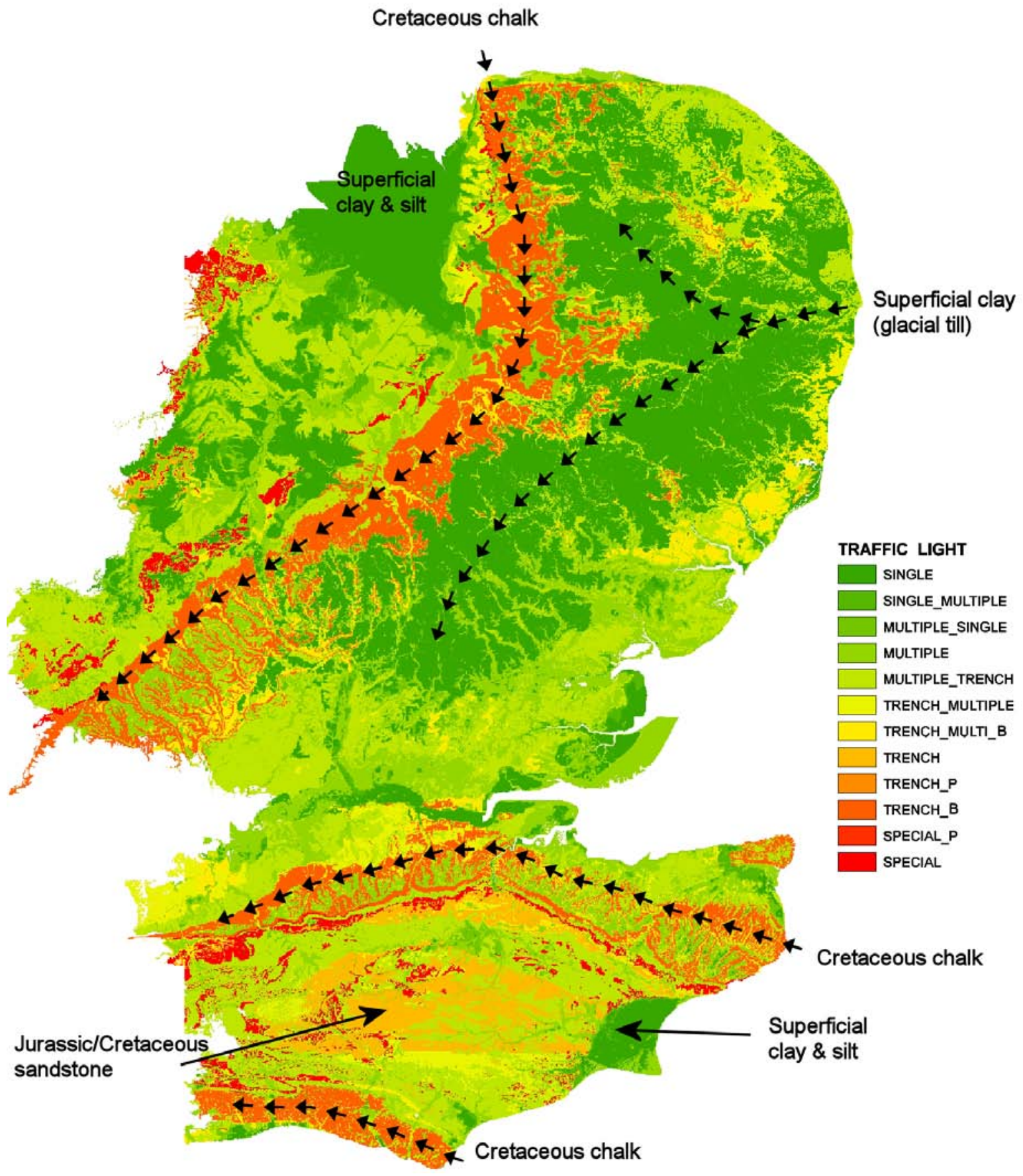

Figure 9 


\begin{tabular}{|c|c|}
\hline Dataset & Description \\
\hline BGS DigMapGB50 & $\begin{array}{l}\text { National digital geology map at } 1: 50,000 \text { scale comprising superficial and } \\
\text { bedrock geology. This provides spatial variability of geology, and provides } \\
\text { the basic litholological parameters upon which strength and resistivity data } \\
\text { are collated. }\end{array}$ \\
\hline $\begin{array}{l}\text { BGS Soil Parent } \\
\text { Material dataset }\end{array}$ & $\begin{array}{l}\text { National digital geology map at } 1: 50,000 \text { scale of the first recognisably } \\
\text { geological deposit beneath the soil layer. This provides spatial variability of } \\
\text { near-surface geology and weathering parameters such as strength, texture } \\
\text { etc. }\end{array}$ \\
\hline $\begin{array}{l}\text { NSRI National Soil Map } \\
\text { (NATMAP) }\end{array}$ & $\begin{array}{l}\text { National digital soil map at } 1: 250,000 \text { scale. This provides spatial variability } \\
\text { of soil in terms of, texture, soil water regime, soil parent material, depth and } \\
\text { stoniness and is enhanced with attribution of soil resistivity, soil depth and } \\
\text { 'excavatability' parameters. }\end{array}$ \\
\hline $\begin{array}{l}\text { NSRI 25k and 50k } \\
\text { detailed soil maps }\end{array}$ & $\begin{array}{l}\text { Local detailed digital soil maps at } 1: 25,000 \text { and } 1: 50,000 \text { scale that provide } \\
\text { spatial variability of soil types, (including texture, soil water regime, soil } \\
\text { parent material) and enhanced with attribution of soil resistivity, soil-depth } \\
\text { and 'excavatability' parameters. }\end{array}$ \\
\hline $\begin{array}{l}\text { BGS Superficial } \\
\text { deposit thickness map }\end{array}$ & $\begin{array}{l}\text { National digital map at 1:50,000 scale that provides spatial variability of the } \\
\text { thickness of superficial deposits and is used in calculating penetration } \\
\text { depths. }\end{array}$ \\
\hline Resistivity data & $\begin{array}{l}\text { BGS National Resistivity Sounding Database comprising } 8,200 \text { electrical } \\
\text { soundings and modelled data compiled into a database of resistivity values } \\
\text { for each soil and geology type. }\end{array}$ \\
\hline Engineering data & $\begin{array}{l}\text { BGS National Geotechnical Database and site investigation borehole } \\
\text { records used to compile a database of engineering values for each soil and } \\
\text { geology type. }\end{array}$ \\
\hline
\end{tabular}

Table 1

\begin{tabular}{|l|c|}
\hline \multicolumn{1}{|c|}{ Description } & Abundance (\%) \\
\hline Stoneless & $<1$ \\
\hline Very slightly stony & $1-5$ \\
\hline Slightly stony & $6-15$ \\
\hline Moderately stony & $16-35$ \\
\hline Very stony & $36-70$ \\
\hline Extremely stony & $>70$ \\
\hline
\end{tabular}

Table 2 